\title{
Analysis of Using Multimodal Feedback in Writing Instruction from EFL Learners' Perspective
}

\author{
Ying Zhang ${ }^{1}$ \\ ${ }^{1}$ English Department, North China Electric Power University, Baoding, Hebei Province, China \\ Correspondence: Ying Zhang, English Department, North China Electric Power University, Baoding, Hebei \\ Province, China.
}

Received: October 18, 2018 Accepted: November 8, 2018 Online Published: November 28, 2018

doi:10.5539/ells.v8n4p21 URL: https://doi.org/10.5539/ells.v8n4p21

\begin{abstract}
The present study aims to investigate EFL learners' perceptions of multimodal feedback on writing and their use of screencast feedback in revision. Six English majors participated in the case study for 8 weeks. In analyzing diaries and the follow-up interview, it was found that participants reported a positive attitude towards the use of screencast feedback on writing. The audio-visual feedback was viewed as beneficial in motivating and engaging students in writing. The multimodal comments were effective to meet students' diverse needs and build up the relationship between teacher and students. It was also reported by the participants the potential value of using screencast feedback to encourage students to take active actions in revision.
\end{abstract}

Keywords: multimodalilty, writing feedback, EFL learners, screencast

\section{Introduction}

Feedback plays a significant role in writing instruction. As claimed by Hyland and Hyland (2006), "the issue of feedback has long been regarded as essential for the development of ESL writing skills" (p.8). For EFL learners, English writing, as a comprehensive skill, is a quite demanding task. Compared with the lack of vocabulary and misuse of grammar, students face more difficulties in organizing the structure by the internal logic and employing coherence devices to connect ideas. Additionally, assessing English writing has long been a big challenge for both EFL learners and practitioners. Despite the great deal of time spent in practicing English writing, the gained reward is limited.

Some teachers complain that students lack engagement in feedback and that the huge endeavor they've made does not seem to yield fruitful results. On students' part, they suffer from their misinterpretation of teacher's written feedback and feel frustrated by the ineffective guidance of the teacher. However, the fact is that the potential function of feedback on writing is not fully realized in traditional pedagogic writing practice. On one hand, the process of giving feedback is regarded as time-consuming in which teachers have to make decisions on the extent of explicitness of comments. Teachers usually struggle with offering clear and informative feedback through written words. On the other hand, the process of interpreting written feedback becomes a cognitive load for students, which leads to inefficiency. This may due to the limitations of the written feedback which fails to meet the diverse needs of students with different learning styles and preferences (Bitchener \& Ferris, 2012). Thus, the written feedback is even not read by many students (Rust, O'Donovan, \& Price, 2005). In the digital era, the fast development of educational technologies provide more audio-visual aids to writing teachers who are enabled to deliver feedback and convey meanings in a multimodal way.

Some research showed the potential advantages of using technology-enhanced feedback (Cope, et al 2011; Pollock, 2011). With video feedback, students can manage their learning at own pace and get access to the feedback more conveniently (Brick \& Holmes, 2008), and they get a better understanding of teacher's commentary and become more active to get involved in the process of revising writing papers (Thompson \& Lee, 2012). For example, screencasting is used to offer feedback in a dialogic style through digital video-recordings. It makes easy to record videos accompanied by a narration comments recorded. Some studies investigating this new mode of feedback on writing found positive results (Ali, 2016; West \& Turner, 2016; Hynson, 2012; Moore \& Filling, 2012). However, the empirical studies exploring the use of screencasting to provide feedback in foreign language teaching contexts are rather limited. In China, most teachers still use the traditional written feedback in isolation to offer guidance for their EFL students in the writing instruction which is proven to be in 
low efficiency. Therefore, the current study aims to investigate Chinese EFL learners' perceptions of integrating screencast feedback in writing process and the use of multimodal comments in revision.

\section{Literature Review}

\subsection{The Role of Feedback in Writing Process}

High quality feedback is of great importance in improving students' learning and performance (Evans, 2013; Ferguson, 2011; Hattie \& Timperley, 2007). In L2 writing research, the provision of feedback has been one of the hot debated topics. Despite the critical role of feedback in L2 writing, how to offer feedback effectively remains in discussion. Several basic qualities of effective feedback are generally recognized in previous research, for example, informative content, interactions between teacher and students, timely provision, students' engagement (Evan, 2013; Brown, Harris, \& Harnett, 2012; Gibbis \& Simpson, 2004; Hattie \& Timperley, 2007; McGarrell \& Verbeem, 2007).

First, effective feedback should provide comments including both the macro-level and the micro-level (Walker, 2009). The focus of feedback should be on meaning rather than on form, for the primary purpose of writing is for communication (Mc Garrell \& Verbeem, 2007). It indicates that high-quality feedback should focus on the communicative content of the writing. Hattie \& Timperley (2007) claims that effective feedback should convey information about "progress, and/or about how to proceed" (p. 89). That means feedback should inform learners of what to do and how to do. Therefore, teachers are expected in the feedback to provide students with adequate information and clear directions for revision.

Second, effective feedback should promote interactions between teacher and students (Nicolson 2010). To encourage dialogues between teacher and students, conference is an ideal way of instruction. Previous studies showed a positive attitudes held by students toward the feedback received through face-to-face dialogues with teacher (Price et al., 2010; Van der Schaaf et al., 2013). However, the conference might not be always possible in practical instruction because of the time limitation. Alternatively, teacher-students dialogues may take place in other more accessible forms.

Third, students give preference to prompt feedback (Ferguson, 2011). It is advisable that feedback be provided quickly after students have accomplished their assignment, otherwise less focus is put on the feedback by students (Gibbs \& Simpson, 2004). However, in daily instruction, teachers usually have to shoulder a heavy load to handle large classes to meet the tight schedule. Meanwhile, they struggle with providing a detailed comment in a clear way through written words. Students may become impatient with the untimely feedback and have difficulties in decoding the written comments given by the teacher.

Fourth, effective feedback should motivate students to engage in the revision process (Gibbs \& Simpson, 2004). Teachers should not take it for granted that students will act upon their writing when they receive the feedback (Sadler, 1989). Actually, it is very difficult for teachers to monitor students' follow-up behaviors. For one thing, the immense mark-ups and corrections that are included in the traditional feedback may make students feel very frustrated about their low proficiency levels. Another, different learning styles and preferences held by students may affect their learning behaviors. For example, some students may be more engaged and efficient when receiving comments through written mode, while others may prefer oral feedback through dialogues. In traditional feedback, teachers could not effectively cater to students' individualized needs and expectations through written mode (Bitchener \& Ferris, 2012). Effective feedback should help students maintain their self-esteem and motivation so as to get students actively involved in the revision process (Nicol \& Mc Farlane-Dick, 2004).

The limitations of traditional mode of feedback and challenges faced by teachers and students in writing could be addressed by providing enhanced feedback through integrating modern educational technologies (Cope, Kalantzis, McCarthey, Vojak, \& Kline, 2011; Hattie \& Timperley, 2007; Pollock, 2011).

\subsection{Multimodality in Feedback Provision}

Different from written mode of feedback, multimodal feedback provides improved quality of information through a combination of graphic, text and voice. The variation of modes helps learners gain a better insight into teacher's review and assessment that go beyond simple correction and editing, and it shortens the distance between students and teacher (Hope, 2011). One tool of realizing multimodal feedback is to use screencasting which enables teachers to use screen-capture videos accompanied by audio comments to guide students in writing. With audio-visual aids, it is convenient for teachers to address students' errors in the lower level of language use and add comments on the higher level of writing skills. For students, screencasting is "particularly useful where step-by-step processes are being explained and students can watch, pause and assimilate as they 
progress through the production" (Wakeman 2013, p. 3). It shows the advantage that students have to manage and monitor their own learning.

Previous research has explored the potential value of using screencasting in providing multimodal feedback. One of the problems for EFL writers is their difficulties in understanding teacher's feedback which is characterized as "vague, poorly expressed, and even, sometimes, illegible" (Brick \& Holmes, 2008, p. 340). With audio-visual aids, teachers are enabled to say more to provide comments and suggestions in detail. Thompson and Lee (2012)'s study showed that students preferred audio-visual feedback which is more meaningful and more conversational thus more understandable. In addition to the increased quantity of feedback, this audio-visual feedback is particularly useful for teachers to record their comments on the overall content and general structure from a global perspective. It provides multimodal information for students to receive clear and specific guidance and to promote their understandings (Ali, 2016; Harper et al., 2015). This is in line with Stannard (2008)'s findings that screencast feedback is rich and helpful for students with different needs and learning preferences to enhance their understandings. In Ali (2016)'s study, there is an obvious difference in writing performance between students who received screencast feedback and students who received traditional written feedback. The former groups tend to outperform the latter group in higher level concerns of writing. West and Turner (2016) also found enhanced guidance for students with screencast and students' better engagement in the revision process.

Meaningful relationship between teacher and students is crucial in conducting effective teaching (Campbell, Breanne \& Feldmann, 2017). Prior studies have indicated that screencast feedback is beneficial to maintain stronger relationship between teacher and students. Compared with face-to-face conferences, feedback offered through videos makes students feel less stressful since it is given in a personal and private manner (O'Malley, 2011). Ruffini (2015) found that students preferred screencast feedback because of greater flexibility. They could take more control over their writing flow with the guidance of recordings. Different from reading written feedback that lets students feel overwhelming, students like watching screencast recordings that are played in a conversational tone under a teacher-present atmosphere. Students also feel more respected and positive with teacher's care and engagement (Anson et al., 2016). Thus, screencast feedback enhances the quality of interactions between teacher and students in writing (Campbell \& Feldmann, 2017). Thomson and Lee (2012) found that students are enabled to better interpret the teacher's commentary and be more ready to take actions in writing practice. Besides, with audio-visual aids, the teacher's scaffolding activities become more explicit and meaningful which are easy for students to get access to (Campbell \& Feldmann, 2017).

Some studies that explored learners' perceptions of multimodal feedback seem to reveal a generally positive attitude held by students toward using screencast feedback. Students in West \& Turner's (2016) study regarded received screencasts as clear and easy to understand, thus a preferred form of feedback. The multimodality nature of screencast feedback makes it better satisfy students' needs with different learning styles. Similarly, Ali (2016) also found that students viewed screencast feedback as more constructive and engaging. Students in Ducate and Arnold's (2012) study were found to make use of audio-visual recordings in their writing more frequently than using written feedback. Besides, screencast feedback was found to be more memorable to enable students to have a high retention of teachers' explanations and comments (Harper et al, 2015).

Despite the advantages of using screencast feedback, there are also some concerns deserving further discussions. One of the concerns is about the time. Students may not use screencast feedback effectively if it requires too much time decoding it (Goldstein, 2004). Another challenge is about students' use of screencast feedback in their revision process. In Elola and Oskoz's (2016) study, students were found to make similar revisions using either screencast feedback or written feedback. Summarizing previous research, studies investigating the use of screencast feedback in foreign language writing context are few, especially the understanding of potential values of screencasting for EFL learners and their perceptions of the use of multimodal feedback in writing instruction.

\section{Method}

\subsection{Participants}

The study was conducted in a university of science and engineering in China. Six English major students participated in the present case study. The participants were voluntary and informed of the purpose of the study by the instructor. All of the participants were native speakers of Chinese, and English is learned as their foreign language. On average, the six students have learned English for more than 10 years. At the time of the study, they were in their third semester of English writing class. The class was scheduled twice a week with 100 minutes per time for 8 weeks. Before participating in the present study, the students reported that all of the previous feedback was provided in written mode, and they had no experience of receiving any multimodal 
feedback. The instructor, who had been teaching English writing for seven years, was willing to try effective ways of giving feedback to engage students in writing.

\subsection{Instrument}

Three instruments were employed to collect data in the present study.

First, the screencast feedback was recorded through Jing ${ }^{\circledR}$ software which is simple to use and could record the actions on a computer screen and the instructor's voice at the same time. Jing ${ }^{\circledR}$ software requires little effort to install and maintain. With the URL address provided by Jing®software that could be shared with others, the online digital videos are easily accessible. Instructors could store the recorded videos on the website and email the address to students to distribute the feedback. Before conducting the study, the needed Jing®software and other necessary hardware were downloaded and installed for the instructor to record digital feedback. To ensure the quality of the study, the instructor was trained to improve the proficiency in using the software to record feedback. A rubric was employed as a guide in evaluating students' writing. The participants were also provided with the rubric.

Second, participants were requested to keep a diary of their experiences of using screencast feedback. The diary was employed as a reflective data to capture participants' feelings and thoughts about using screencast feedback and how they make use of the multimodal feedback to revise their draft. Some basic guidelines of writing diary were given to the participants. For example, the diaries should depict their revision process. The diaries should include their experiences of advantages and problems in using screencast feedback. The diaries were written in participants' $\mathrm{L} 1$ in order to elicit more relevant information.

Third, a semi-structured individual interview was conducted to explore more information about participants' use of screencast feedback. The interview was recorded and transcribed later. Five open-ended questions were designed to encourage participants to talk about their use of screencast feedback:

(1) How do you feel about screencast feedback?

(2) Compared with traditional written feedback, are there any advantages of using this multimodal feedback?

(3) How do you make use of the screencast feedback to help you revise your writing?

(4) What are your problems or difficulties in using screencast feedback?

(5) Do you have anything else to say about using screencast feedback in writing

\subsection{Procedures}

Throughout the 8 weeks of writing class in the semester, participants were assigned to accomplish four argumentative writings of 250 words in length. After completion of each first draft, participants were required to deliver it to the instructor through email. Then the instructor made use of Jing ${ }^{\circledR}$ software to record the screencast feedback. While making audio-visual commentary, the instructor focused on both the macro level and the micro level. From the global perspective, the comments and evaluation were focused on content, structure and general organization. The local commentary of concrete language use was also included. All the feedback was given in participants' L1 and was provided to participants before they get started with revision. On receiving feedback, participants were required to revise their first draft within seven days. Following each revision, participants were required to write a diary about their revision activities and their experience of using the received screencast feedback. Participants were informed that their essays and diaries were used for research purpose and would not influence their final assessment of the class. Follow-up interviews were conducted respectively in the final stage after the revision of all the four writing essays was accomplished. Each interview was lasted for 20 minutes and the whole process was recorded by the researcher.

\subsection{Data Collection and Analysis}

The diaries were collected and interpreted after each revision section, and the interview was transcribed in the final section of the study. To transcribe the qualitative data, the content analysis (Allison, 2002) was employed. Through reviewing and comparing the reflective information that participants reported or wrote, the researcher analyzed and grouped the themes into different categories of participants' perceived advantages and disadvantages of using screencast feedback. In some confusing categories, the perspective of interview helped gain a deeper understanding and of participants' attitudes and their revision behaviors. Cross-checking was repeated to improve the quality of data transcription. 


\section{Results and Discussion}

\subsection{Students' Perceptions of Screencast Feedback}

Participants generally held a positive attitude towards the use of screencast feedback and preferred to use it to guide their revision in writing. This was indicated in both their diaries and the follow-up interview.

It (screencast feedback) is quite different from written feedback. I like it. (Student 2)

I prefer to use it (screencast feedback). (Student 3)

Screencast feedback is effective. (Student 5)

This is in line with findings in prior research that students regard screencast as helpful and efficient in their writing (Ali, 2016; Harper et al., 2015; Stannard, 2007; Thompson and Lee, 2012). Further investigation into participants' perceptions revealed the underlying reasons for it.

All the participants attributed their preference to the clear commentary provided by screencast feedback and its ease of understanding.

I often feel confused about the meanings of red circles and question marks made by the teacher in written feedback. This new form of feedback is quite clear. I could understand what needs to be changed. (Student 1)

It is very helpful. The teacher gives very clear and sufficient explanations of my problems and I know how to revise. (Student 2)

It became easier to understand when I follow the mouse pointer in the screen while listening to teacher's comments. (Student 4)

I could pause at any moment I want to. And when I could not understand the comment, I could always rewind the video and watch it again. That's very helpful. (Student 6 )

Participants' comments on the enhanced understandings of the feedback provided through screencating are consistent with Moreno and Mayer (2002)'s claim about alleviating learners' cognitive load with audio-visual aids. The multimodal feature of screencast feedback facilitates students' comprehension of the received information from various sources. Another benefit is that compared with the overwhelmingly mark-ups included in written feedback, the audio-visual feedback could convey more information clearly with efficiency to students. Anson et al. (2016) measured that 745 words could be included in a 5-min screencast feedback in contrast to only 109 words included in a textual feedback on an essay. That indicates that the teacher is allowed to provide more detailed explanations adequately in a short time using screencasting. As discussed by Stannard (2007), the multimodal feedback conveys both textual and audio messages in a greater density. In addition to the clear commentary and rich multimodal information, students also reported the increasing guidance in screencast feedback from the higher level of orders.

From the teacher's suggestions, I have more ideas about how to make my claims more persuasive. (Student 2)

I find the feedback from the perspectives of content and structure is more valuable than simply editing the language errors. (Student 3)

From the comments given by the students, it can be inferred that teacher's feedback on the level of general content, structure and organization enables students to take a more comprehensive view of their writing, which is of great benefit for students to focus on expressing meaning in their essays to improve their writing proficiency.

Another merit of using screencast feedback reported by the participants is its interactive manner.

It just like the teacher is in front of me and talking about my essay. It is fun. (Student 1)

I prefer the conversational way of receiving the teacher's comments on my essay. It made me feel much more comfortable than talking about my essay face-to-face with the teacher. (Student 4)

Screencast feedback makes the teacher's thoughts visible. It makes me feel that the teacher and I are working together to solve problems. (Student 6)

The result shows that screencast feedback fosters the connection between teacher and students. Instead of simply correcting or editing the paper, the teacher is enabled to communicate with students from a reader's perspective and to give targeted guidance to meet students' individual needs. Although it is a one-way communication, it functions in a personal and dialogic pattern which makes students feel real and relevant. This finding seems to be consistent with previous research that screencast feedback tends to be more conversational (Anson el al., 2016). Thus, it may be viewed as an alternative to compensate for the restrictions exerted by actual teacher-students 
conference.

The use of screencast feedback was also found to be positive and encouraging for students. First, the tone of the audio-visual feedback sounds more supportive that helps reduce students' interpretations of teacher's message in a negative way. As reported by one of the participants:

I don't feel like reading written feedback, because there are too many red mark-ups that make me feel frustrated. Actually, I think that negative comments are better accepted when being spoken to in videos. (Student 4)

It can be inferred that the audio-visual feedback has an advantage over written feedback in conveying message in a less overwhelming way that provides students with more affective support. Students may also develop a more appropriate attitude towards receiving teacher's feedback. This supports the finding in Thomson and Lee (2012)'s study that explicit feedback through videos contributes to students' enhanced affective motivation. Second, screencasting allows teachers to make more meaningful and in-depth suggestions from the macro level. Compared with the feedback on the micro-level focusing on the lower order of language use, the meaning-focused feedback works more effectively to motivate students to recognize the distance between the goal and the reality and provides helpful directions for them to bridge the gap. Student 5 wrote in her diary that "It makes more sense for me when I get help from teacher's comments on how to communicate ideas rather than on just correcting grammar errors". Similar findings were found in Cavanaugh and Song (2014)'s study that students are more interested in the feedback provided from the global perspective. In addition, participants also talked about the increased engagement in writing upon receiving screencast feedback:

It is very understandable. I'd like to watch the video and make revisions on my paper at the same time. (Student 1)

I put down teacher's suggestions step-by-step while watching the feedback. I pause and rewind the video to catch the key points. (Student 3)

I usually watch the feedback twice. For the first time, I catch a big picture of my writing. For the second time, I make revisions accordingly. (Student 4)

These remarks indicate that students are willing to spend time watching teacher's comments and engaging themselves in making improvements on their draft. This is also reported in previous study that teacher's explicit explanations improve students' engagement (Evans, 2013; Thompson \& Lee, 2012). As mentioned by one participant, some of the engagement goes beyond the writing task on the spot. "The comments are very valuable not only for improving the present paper but also for improving my overall writing skills, so I will review some for the following writing task." Students' promoted follow-up actions and engagement in their writing may be accounted from the changed form of teacher's feedback from being summative to being more formative through recordings. Another encouraging factor for participants is the personalized and private way of receiving feedback.

The feedback is very specific and targeted. I tend to spend more time watching videos and revising my paper. If I don't work hard to improve my writing, then it is my problem. (Student 1)

The teacher is addressing my problem in detail that makes me feel important and cared about, so I am careful of revising my paper... I usually replay it whenever I want to. (Student 4)

It is more targeted and valuable to receive teacher's comment aimed at my problems. It is just like talking to the teacher in person, but better than in-class feedback because I am the only audience.(Student 5)

The data reveals that screencasting enables the teacher to provide feedback to meet personalized needs. It is conducive for students to have a sense of being personal and relevant that motivates them to be proactive and to invest time in improving writing skills. The private manner also works to maintain their self-esteem which facilitates their actions to exert effort in writing. This finding is in agreement with previous study that the multimodal feedback provides personal and motivating message to satisfy learners' different needs (Elola \& Oskoz, 2016).

\subsection{Students' Use of Screencast Feedback in Revision}

Participants' use of screencast feedback in revision process was also revealed in their diaries and follow-up interviews.

It was found that clear decoding of teacher's feedback is a prerequisite in making students take actions to revise their writing. As reported by the participants, "I check the highlighted part back and forth with the moving of the cursor, it is very clear". This indicates that the audio-visual feedback could take advantages of diverse modes of 
textual, audio and visual information to make the comments easily understandable, which greatly satisfies the various needs of learners (Brick \&Holmes, 2008). Besides, the instructor could give more explanations freely through verbal comments. "The teacher gives a lot of examples, then I just follow the suggestions to make changes". The clear comments direct students' actions to obtain their goal by informing them of what to do and how to do.

On the basis of better understandings of the requirements and expectations, students also reported an increased efficiency in their revision actions.

Now I can easily locate the specific problem and change it at once while listening to the teacher's comment. However, in the past, I might not bother with revising my paper after reading the comments at the end of the paper and then going back to find out the exact place that needs revision (Student 3)

It is efficient because the teacher is helping me with specific problems in the process of writing but not giving a very vague evaluation on my overall writing proficiency. (Student 4)

The revision behaviors noted by students show that in videos, teacher's targeted guidance in the writing process was effective in helping students to read the feedback purposefully and act upon their papers accordingly. This is consistent with the prior finding that students like watching video feedback to make revision (Turner \& West 2013). Students also mentioned that they made revisions on both their mechanic problems and on their textual organizations.

I used more connecting words to make the ideas more coherent. (Student 1)

As told by the teacher, I added a topic sentence in the paragraph and categorized the following contents into three different groups to support my view. (Student 2)

In the conclusion paragraph, I put forward further suggestions to address the present problem.(Student 4)

I changed the run-on sentences into a couple of separate sentences and corrected the errors in punctuation. (Student 6)

Through the analysis of self-reported data, it can be found that the students made improvements throughout the whole paper with the aid of the received video feedback. They made revisions to use accurate language and punctuation and express meanings in a cohesive and coherent way. Additionally, they worked on the general organization of the content and structure, which is of great significance for the enhancement of the overall writing quality and writing skills.

Some participants also mentioned problems of using audio-visual feedback in revision. One student said, "I find it inconvenient to go back to a certain problem in the former part. I have to search from the very beginning." Another student mentioned, "Sometimes the teacher is talking too fast to follow. I have to pause several times before going to the next part." These comments suggest that teachers need to consider the limitations of using screencast feedback and work on possible strategies to address these problems. For example, it is reasonable for teachers to keep a relatively slow speed and to pause when necessary in delivering feedback to allow students to make responses.

\section{Conclusion}

The present study explored Chinese EFL learners' perceptions of multimodal feedback on writing and their use of screencast feedback in revision. The findings revealed that participants generally held a positive attitude towards the employment of screencast feedback in writing process. The multimodal feedback was viewed as clear, specific and comprehensive which was conducive in motivating and engaging students in revision. The audio-visual feedback was also reported to be beneficial in developing close connections between teacher and students, and it was effective in promoting students' follow-up actions and responses in revising their draft.

As the sample size is small and the experimental time is rather limited, the findings of the current study should be interpreted with caution. Further studies may require larger samples covering more genres to investigate students' specific use of screencast feedback in revision and the relationship between students' revision with audio-visual aids and their writing performance and writing qualities.

\section{Acknowledgments}

This research was supported by "the Fundamental Research Funds for the Central Universities" (2015MS68).

\section{References}

Ali, A. D. (2016). Effectiveness of using screencast feedback on EFL students' writing and perception. English Language Teaching, 9(8), 106-121. https://doi.org/10.5539/elt.v9n8p106 
Allison, D. (2002). Approaching English Language Research. Singapore University Press, Singapore

Anson, C. M., Dannels, D. P., Laboy, J. I., \& Carneiro, L. (2016). Students' perceptions of oral screencast responses to their writing exploring digitally mediated identities. Journal of Business and Technical Communication, 30(3), 378-411. https://doi.org/10.1177/1050651916636424

Bitchener, J., \& Ferris, D. (2012). Written Corrective Feedback in Second Language Acquisition and Writing. New York, NY: Routledge. https://doi.org/10.4324/9780203832400

Brick, B., \& Holmes, J. (2008). Using screen capture software for student feedback: Towards a methodology using screen capture software for student feedback. Paper presented at the IADIS International Conference on Cognition and Exploratory Learning in Digital Age (CELDA 2008), Freiburg, Germany.

Brown, G. T. L., Harris, L. R., \& Harnett, J. (2012). Teacher beliefs about feedback within an assessment for learning environment: Endorsement of improved learning over student well-being. Teaching and Teacher Education, 28(7), 968-978. https://doi.org/10.1016/j.tate.2012.05.003

Campbell, B. S., \& Feldmann, A. (2017). The Power of Multimodal Feedback. Journal of Curriculum, Teaching, Learning and Leadership in Education, 2(2), 1-6.

Cavanaugh, A. J., \& Song, L. (2014). Audio feedback versus written feedback: instructors' and students' perspectives. MERLOT Journal of Online Learning and Teaching, 10(1), 122-138.

Cope, B., Kalantzis, M., McCarthey, S., Vojak, C., \& Kline, S. (2011). Technology mediated writing assessments: Principles and processes. Computers and Composition, 28(2), 79-96. https://doi.org/10.1016/j.compcom.2011.04.007

Ducate, L., \& Arnold, N. (2012). Computer-mediated feedback: Effectiveness and student perceptions of screen-casting software versus the comment function. In G. Kessler, A. Oskoz, \& I. Elola (Eds.), Technology across writing contexts and tasks (Vol. 10, pp. 31-56). San Marcos, TX: CALICO.

Elola, I., \& Oskoz, A. (2016). Supporting second language writing using multimodal feedback. Foreign Language Annals, 49(1), 58-74. https://doi.org/10.1111/flan.12183

Evans, C. (2013). Making sense of assessment feedback in higher education. Review of Educational Research, 83(1), 70-120. https://doi.org/10.3102/0034654312474350

Ferguson, P. (2011). Student perceptions of quality feedback in teacher education. Assessment \& Evaluation in Higher Education, 36(1), 51-62. https://doi.org/10.1080/02602930903197883

Goldstein, L. M. (2004). Questions and answers about teacher written commentary and student revision: teachers and students working together. Journal of Second Language Writing, 13(1), 63-80. https://doi.org/10.1016/j.jslw.2004.04.006

Harper, F., Green, H., \& Fernandez-Toro, M. (2015). Using screencasts in the teaching of modern languages: Investigating the use of Jing ${ }^{\circledR}$ in feedback on written assignments. The Language Learning Journal, 1-18.

Hattie, J., \& Timperley, H. (2007). The power of feedback. Review of Educational Research, 77(1), 81-112. https://doi.org/10.3102/003465430298487

Hope, S. A. (2011). Making movies: The next big thing in feedback? Bioscience Education, 18.

Hyland, K., \& Hyland, F. (Eds.). (2006). Feedback in second language writing: Contexts and issues. New York, NY: Cambridge University Press. https://doi.org/10.1017/CBO9781139524742

Hynson, Y. T. A. (2012). An innovative alternative to providing writing feedback on students' essays. Teaching English with Technology, 12(1), 53.

Mc Garrell, H., \& Verbeem, J. (2007). Motivating revision of drafts through formative feedback. ELT Journal, 61(3), 228-236. https://doi.org/10.1093/elt/ccm030

Moore, N. S., \& Filling, M. L. (2012). iFeedback: Using video technology for improving student writing. Journal of College Literacy \& Learning, 38, 3-14.

Moreno, R., \& Mayer, R. E. (2002). Verbal redundancy in multimedia learning: When reading helps listening. Journal of Educational Psychology, 94(1), 156-163. https://doi.org/10.1037/0022-0663.94.1.156

Nicol, D., \& Macfarlane-Dick, D. (2004). Rethinking formative assessment in HE: a theoretical model and seven principles of good feedback practice. Retrieved from http://elektra.myblog.arts.ac.uk/files/2015/01/Rethinking_formative_assessment_in_he1.pdf 
Nicolson, M. (2010). Teaching Through Assessment (Internal Induction Pack for Associate Lecturers). Edinburgh: The Open University in Scotland.

O'Malley, P. J. (2011). Combining screencasting and a tablet PC to deliver personalised student feedback. New Directions, 7, 27-30. https://doi.org/10.29311/ndtps.v0i7.464

Pollock, J. E. (2011). Feedback: The hinge that joins teaching and learning. Thousand Oaks, CA: Corwin Press.

Price, M., Handley, K., Millar, J., \& O’Donovan, B. (2010). Feedback: All that effort, but what is the effect? Assessment \& Evaluation in Higher Education, 35(3), 277-289. https://doi.org/10.1080/02602930903541007

Ruffini, M. F. (2012). Screencasting to engage learning. Educause Review Online. Retrieved from $\mathrm{http}: / / \mathrm{www}$.educause.edu/ero/article/screencasting-engage-learning

Rust, C., O’Donovan, B., \& Price, M. (2005). A social constructivist assessment process model: how the research literature shows us this could be best practice. Assessment and Evaluation in Higher Education, 30(3), 233-241. https://doi.org/10.1080/02602930500063819

Sadler, D. R. (1989). Formative assessment and the design of instructional systems. Instructional Science, 18, 119-144. https://doi.org/10.1007/BF00117714

Stannard, R. (2008). Screen capture software for feedback in language education. Paper presented at the Second International Wireless Ready Symposium, NUCB Graduate School, Nagoya.

Thompson, R., \& Lee, M. J. (2012). Talking with students through screencasting: Experimentations with video feedback to improve student learning talking with students through screencasting: Experimentations with video feedback to improve student learning. Journal of Interactive Technology and Pedagogy.

Van Steendam, E., Rijlaarsdam, G., Sercu, L., \& Van den Bergh, H. (2010). The effect of instruction type and dyadic or individual emulation on the quality of higher-order peerfeedback in EFL. Learning and Instruction, 20, 316-327. https://doi.org/10.1016/j.learninstruc.2009.08.009

Wakeman, C. (2013). The innovative use of screencasts in higher education. Innovative Practice in Higher Education, 1(3), 1-5.

Walker, M. (2009). An investigation into written comments on assignments: do students find them usable? Assessment and Evaluation in Higher Education, 34(1), 67-78. https://doi.org/10.1080/02602930801895752

West, J., \& Turner, W. (2016). Enhancing the assessment experience: improving student perceptions, engagement and understanding using online video feedback. Innovations in Education and Teaching International, 53(4), 400-410. https://doi.org/10.1080/14703297.2014.1003954

\section{Copyrights}

Copyright for this article is retained by the author, with first publication rights granted to the journal.

This is an open-access article distributed under the terms and conditions of the Creative Commons Attribution license (http://creativecommons.org/licenses/by/4.0/). 